\title{
O USO DA RESERVA BIOLÓGICA DO TINGUÁ POR UMA ESCOLA EM SEU ENTORNO PARA A PROMOÇÃO DA EDUCAÇÃO AMBIENTAL
}

\author{
Guilherme Preato Guimarães ${ }^{1}$ \\ Edileuza Dias de Queiroz ${ }^{2}$
}

\begin{abstract}
RESUMO
O uso público em Áreas Protegidas e Unidades de Conservação (UC) no Brasil, é um tema muito debatido e reformulado desde sua gênese. Percebe-se que o debate se aprofunda quando se trata do uso de UC mais restritivas (parques e reservas) no território brasileiro. Dentre as diversas possibilidades desse uso, pensa-se a promoção da Educação Ambiental in lócus como uma proposta integradora e eficiente ao que se refere às funções sociais desses lugares. Dessa maneira, esse estudo busca uma análise acerca dos resultados encontrados em uma pesquisa monográfica realizada entre os anos de 2016 e 2017, a qual investigou o uso da Reserva Biológica do Tinguá para a promoção da Educação Ambiental por uma escola estadual do seu entorno. Como resultados, percebe-se que essas ações encontram-se em estágio incipiente, carecendo de maior parceria interinstitucional, além da constatação de um padrão de Educação Ambiental embasada na pedagogia conservadora, apontando a necessidade de formação continuada para os professores que participaram da pesquisa.
\end{abstract}

Palavras chave: Unidades de conservação; educação ambiental; uso público

\begin{abstract}
The public use in Protected Areas and Conservation Units (UC) in Brazil has been intensively debated and reformulated since its inception. The debate deepens when it comes to the use of more restrictive UC (parks and reserves), in the Brazilian territory. Among the various possibilities of this use, it is thought the promotion of Environmental Education in loco as an integrative and efficient proposal regarding the social functions of these places. Thus, this study seeks an analysis about the results found in a monographic research conducted between 2016 and 2017, which investigated the use of the Tinguá Biological Reserve for the promotion of Environmental Education by a state school of its surroundings. As a result, it can be seen that these actions are in an incipient stage, lacking a greater inter-institutional partnership, besides the finding of a pattern of Environmental Education based on the conservative pedagogy, pointing out the need for continuous training for the teachers who participated in the research.
\end{abstract}

Keywords: Protected areas; environmental education; public use

\section{INTRODUÇÃO}

A criação e implementação das áreas protegidas em todo o mundo constitui uma das principais formas de intervenção governamental com o propósito de reduzir as perdas da biodiversidade geradas pela exploração desenfreada dos recursos naturais. Os impactos

\footnotetext{
${ }^{1}$ Mestrando em Geografia da Universidade Federal Rural do Rio de Janeiro (PPGGEO-UFRRJ). E-mail: guilherme.geografia.ufrrj@gmail.com

${ }^{2}$ Docente do Curso de Geografia da Universidade Federal Rural do Rio de Janeiro/Instituto Multidisciplinar. E-mail: edileuzaqueiroz@gmail.com
} 
ambientais decorrentes dessa exploração acompanham as sociedades humanas e marcam diversos momentos históricos. Porém, o agravamento dessa problemática vem ocorrendo na sociedade moderna devido aos avanços tecnológicos oriundos do aperfeiçoamento da ciência e dos novos paradigmas econômicos. O período de consolidação da era moderna é marcado por diversas descobertas e invenções, além das grandes revoluções que moldaram não somente o sistema de produção, como também o modo de se pensar e viver. Dessa maneira, temos que:

Com a revolução industrial vieram transformações políticas, culturais, econômicas, sociais e ambientais. A acumulação capitalista e expansão dos mercados foram fundamentais para essas mudanças. A agricultura tornou-se mais especializada para suprir as demandas da indústria Européia. No século XIX, as premissas capitalistas centradas nos significados da produção (terra, trabalho e capital) foram se consolidando e a economia clássica, ao tratar os recursos da Terra como mercadoria, considerava irrelevante a degradação ambiental. Tais ideias aliadas ao incremento industrial promoveram grande avanço da degradação dos recursos naturais e, concomitantemente, redução dos espaços nativos. Os problemas ambientais, além de atingir as colônias por conta da intensiva exploração de recursos, manifestavam-se também nas sedes dos próprios países industrializados. (VALLEJO, 2003, pág. 79)

A degradação ambiental e o modo de vida exaustivo proporcionado pela implantação do modelo urbano-industrial, caracterizado por um crescente quantitativo de pessoas com rotinas de trabalhos fabris, contribuiu para o surgimento dos "...movimentos mais abrangentes de proteção de áreas naturais com a finalidade de uso público" (VALLEJO, 2003, pág. 79). A partir da percepção da alta degradação gerada pelas concentrações urbanas, foram realizados estudos e propostas para a criação de grandes áreas naturais a serem reservadas para a garantia de um ambiente natural, que proporcionasse à população desses centros, locais de recreação em contato com a natureza.

Entretanto, o ato de "resguardar" as áreas naturais não é recente, pois, como aponta Miller (1997, p. 3), “a delimitação de áreas para a preservação de seus atributos naturais evoluiu ao longo da história a partir de suas raízes em atos e práticas das primeiras sociedades humanas". Segundo Thomas (1983) desde o século XVIII já se contestava os direitos ilimitados do homem sobre a natureza.

A criação de um parque nacional integrada à noção vida selvagem (wilderness) ocorreu em 1872 com o Parque Nacional de Yellowstone e serviu como referência para a criação de outros parques semelhantes em diversos lugares pelo mundo. Porém, este modelo apresentava características de exclusão da possibilidade do estabelecimento humano em suas dependências, sendo utilizado apenas para a visitação e lazer das populações urbanas.

No Brasil, o primeiro parque nacional foi criado no ano de 1937 - o Parque Nacional de Itatiaia - e seguiu os mesmos padrões de criação que vinham sendo adotados nos demais países, ou seja, uma área destinada à preservação sendo permitido o uso apenas para o lazer e desenvolvimento de pesquisas científicas.

A reflexão acerca do papel das áreas naturais protegidas, particularmente no caso dos parques e outras unidades de conservação (UC), nos remete à questão do uso público empreendido nesses territórios, sendo um importante objeto de análise. Este uso é primordial, 
seja para a biodiversidade seja para a gestão e devem ser realizados com planejamento, visando reduzir os impactos a fim de manter a qualidade ambiental e de vida da população. Entretanto, muitas UC não têm estrutura para que o uso público seja eficiente, no tocante à conservação da biodiversidade e satisfação dos usuários com o menor impacto possível.

\section{Uso Público: questões conceituais}

O termo 'público' pode ser entendido por diferentes vieses. No contexto deste texto utilizamos o conceito trazido por Rodrigues e Irving (2015, p. 121), que o vinculam “(...) à natureza do espaço preservado, à noção de patrimônio coletivo, ao regime de propriedade e aos serviços que protege". De acordo com o Ministério do Meio Ambiente (2006) o conceito de uso público está associado ao processo de visitação das áreas protegidas, podendo se manifestar como atividades educativas, de lazer, esportivas, recreativas, científicas e de interpretação ambiental, que proporcionam ao visitante a oportunidade de conhecer, entender e valorizar os recursos naturais e culturais existentes. Nesta direção, Pimentel (2013, p. 30) afirma que,

(...) o uso público pode ser conceituado como o uso indireto dos recursos ambientais que se dá sob as diferentes formas de visitação de uma unidade de conservação e, portanto, deve sempre ser orientado pelos preceitos da sustentabilidade e mitigação de seus impactos.

Este conceito traz uma questão muito pertinente para a nossa construção teórica, ou seja, o uso com o menor nível de impacto negativo. Takahashi (2004, p. 25), afirma que as atividades de uso público devem estar sempre vinculadas ao componente educativo para a estimulação do aprendizado do visitante e não o simples entretenimento. Assim, é pertinente investigações acerca dos usos que são realizados (ou não) por escolas sediadas nos entornos de UC.

Queiroz (2018) considera que a Educação Ambiental (EA) precisa ser inserida e efetivada tanto nas escolas quanto nas UC, pois “(...) é uma forte aliada no processo de uso público nas UC, pois é um processo que a médio e longo prazo possibilita programas específicos nesses espaços, contribuindo para a efetivação de práticas sustentáveis". Ressaltamos o grande potencial que esses territórios e seus atores têm para desenvolver práticas de EA, articulando os objetivos da conservação ambiental com os objetivos da transformação social (QUEIROZ, op cit, p. 35).

\section{A RESERVA biOLÓgICA DO TINGUÁ E A PROMOÇÃo DA EDUCAÇÃo} AMBIENTAL

A seguir, serão apresentados os resultados de uma pesquisa monográfica de trabalho de conclusão de curso defendida para alcançar o título de Licenciatura Plena em Geografia, Universidade Federal Rural do Rio de Janeiro, Nova Iguaçu. A pesquisa investigou o uso da Reserva Biológica (REBIO) do Tinguá pelo Colégio Estadual dos Lírios para a promoção da EA, localizado na zona de amortecimento da Reserva no município de Nova Iguaçu, a cerca de 500 metros da sede da UC.

Segundo Silva e Souza (2017), a REBIO Tinguá (Figura 1) é reconhecida como a maior reserva biológica da Mata Atlântica existente no Estado do Rio de Janeiro e tem 
importância porque conserva em seu território trechos importantes de biodiversidade que correspondem a 8\% das florestas protegidas. Com área de 26.260 há, integra a Reserva da Biosfera da Mata Atlântica - RBMA que é reconhecida pela Organização das Nações Unidas para a Educação, a Ciência e a Cultura - UNESCO. Além dos remanescentes florestais, a REBIO conserva mananciais responsáveis pelo abastecimento de água de parte da RMRJ, pois há captações da Companhia Estadual de Águas e Esgotos do Rio de Janeiro (CEDAE).

Figura 1 - Reserva Biológica do Tinguá, RJ

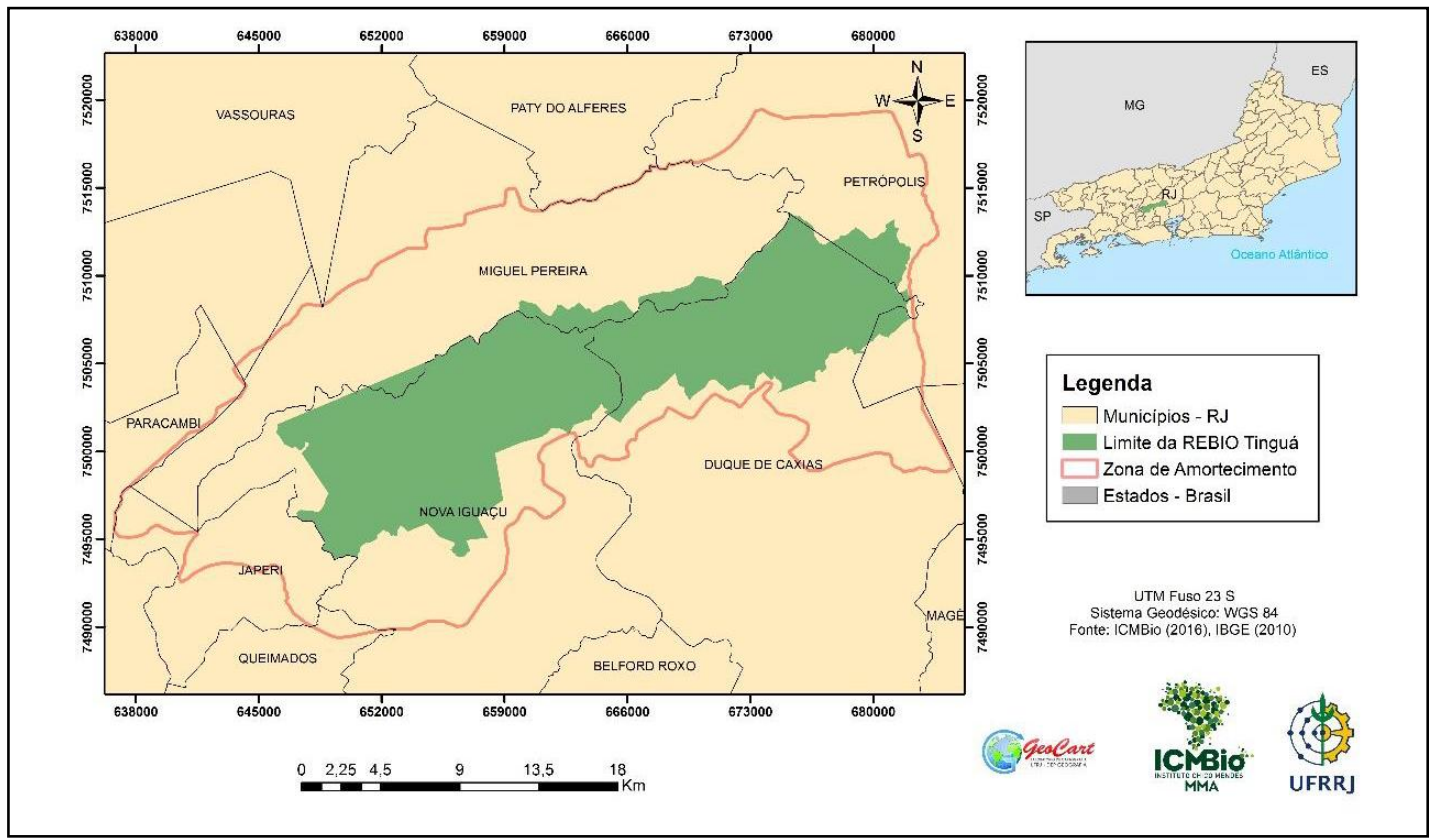

Fonte: Silva e Souza, 2017

O trabalho promoveu uma análise do perfil escolar dos professores, avaliando-se as concepções de educação ambiental desses docentes. Para esse fim, foram empregados questionários semiestruturados aplicados a 13 professores do Colégio Estadual dos Lírios, correspondendo a aproximadamente $80 \%$ do corpo docente. Além disso, foram observadas as aulas e eventos voltados para a temática da EA elaboradas por esses professores.

O questionário foi estruturado em duas etapas: a primeira foi elaborada para traçar os perfis dos professores que aceitaram participar da pesquisa; a segunda etapa buscou investigar suas metodologias de trabalho de acordo com as propostas apresentadas. Para a primeira parte do questionário, foram elaboradas as seguintes questões: Idade; gênero; formação (curso, instituição e ano da graduação); turmas em que atua; disciplina(s) que leciona; há quanto tempo leciona ( $1-3$ anos, $4-6,7-9$, mais de 10 anos); há quanto tempo trabalha na escola (1-3 anos, $4-6,7-9$, mais de 10 anos).

Segundo as respostas, todos os professores participantes da pesquisa possuem idade superior a trinta (30) anos e a maioria, além de ter obtido graduação antes do ano de 2010, é formada em instituição de ensino superior particular e leciona há dez anos ou mais.

A segunda parte do questionário constitui-se com questões acerca das práticas docentes em relação à EA. Para tanto, foram elaboradas as seguintes perguntas: $\mathrm{O}$ que é Educação Ambiental, sob seu ponto de vista? Você trabalha a Educação Ambiental em sua 
disciplina? Na sua opinião, em quais disciplinas pode-se trabalhar as questões ambientais? A escola utiliza a REBIO de Tinguá para trabalhar a Educação Ambiental?

Para análise desses questionários, aplicou-se a metodologia de Análise Textual Discursiva (ATD), pois se trata de uma metodologia vinculada às pesquisas qualitativas e, para além, ela

Assume pressupostos da fenomenologia, de valorização da perspectiva do outro, sempre no sentido da busca de múltiplas compreensões dos fenômenos. Essas compreensões têm seu ponto de partida na linguagem e nos sentidos que por ela podem ser instituídos, implicando a valorização dos contextos e movimentos históricos em que os sentidos se constituem. Nisso estão implicados múltiplos sujeitos autores e diversificadas vozes a serem consideradas no momento da leitura e interpretação de um texto (MORAES; GALIAZZI, 2007, p. 80)

Para além, optou-se por esta metodologia por essa ser uma "abordagem de análise de dados que transita entre duas formas consagradas de análise na pesquisa qualitativa que são a análise de conteúdo e a análise de discurso" (MORAES, GALIAZZI, p. 118, 2006).

Para dar completude a esse trabalho, dividiu-se o viés da Educação Ambiental em categorias de análise, de acordo com os eixos temáticos de educação, buscando uma síntese de sentidos em relação aos referenciais aqui adotados. Destacamos que: "No seu conjunto, as categorias constituem os elementos de organização do metatexto que a análise pretende escrever. É a partir delas que produzirão as descrições e interpretações que comporão o exercício de expressar as novas compreensões possibilitadas pela análise" (MORAES, 2003, p.197).

Ainda acerca dessa categorização, temos que:

Analiticamente, trata-se de discriminar, classificar e interpretar fenômenos ou processos que são diferentes entre si, mas devido a certas semelhanças ou elementos comuns tendem a ser confundidos como uma totalidade homogênea - o que é, inclusive, algo recorrente na Educação Ambiental. Assim, a diferenciação pode produzir um conhecimento mais fiel à realidade do objeto ou processo observado (LAYRARGUES \& LIMA, 2011, p. 3).

Dessa maneira, buscamos o entendimento do eixo Educação Ambiental de acordo com a divisão adotada por OLIVEIRA (2012, págs. 68-73), configurando-se conforme o Quadro I.

As categorias foram pensadas e divididas de acordo com suas características analíticas, de modo que cada qual assume uma metodologia de trabalho partindo de metodologias mais tradicionais/conservadoras até a metodologia crítica. Assim, podemos atribuir a essas metodologias duas macrotendências distintas: a conservacionista/pragmática e a crítica/emancipadora $^{3}$. Ao analisarmos o quadro acima, o item 1.1 estaria mais direcionado às práticas conservadoras enquanto o item 1.5.3, está mais alinhado à pedagogia crítica.

\footnotetext{
${ }^{3}$ Para maior entendimento acerca das macrotendências, ver LAYRARGUES e LIMA (2014)
} 
Com base nas respostas obtidas buscou-se o cruzamento com a teoria das categorias elaboradas, de modo que foram identificadas cinco diferentes concepções de EA, conforme o Quadro II.

Quadro I: Eixo Temático Categorias e Tendências

\begin{tabular}{|c|c|c|}
\hline Eixo Temático & Categ & Idências \\
\hline \multirow{7}{*}{$\begin{array}{c}\text { 1. Concepções de Educação } \\
\text { Ambiental }\end{array}$} & \multicolumn{2}{|c|}{ 1.1 Cognitiva focada no individual } \\
\hline & \multicolumn{2}{|c|}{ 1.2 Romântica, preservacionista } \\
\hline & \multicolumn{2}{|c|}{ 1.3 Comportamentalista } \\
\hline & \multicolumn{2}{|c|}{ 1.4 Sensibilizadora } \\
\hline & \multirow{3}{*}{1.5 Crítica } & 1.5.1 Práxis \\
\hline & & 1.5.2 Relacional \\
\hline & & 1.5.3 Dimensão política \\
\hline
\end{tabular}

Fonte: Os autores, adaptado de Oliveira, 2012

As classificações aqui apresentadas são oriundas de uma análise dos questionários aplicados aos professores do ensino médio da rede estadual, alinhando suas respostas à teoria desenvolvida anteriormente. Ressaltamos que esse alinhamento se deu de forma laboriosa, uma vez que as tendências apresentadas, quando não se complementam, são muito semelhantes em suas definições. Outro fator que dificultou tal alinhamento foram as divergências de ideias nas respostas, provavelmente oriundas da falta de uma compreensão sólida acerca da definição sobre o que é EA e, podemos atribuir essa parca compreensão a diversos fatores, entre eles, ao fato de não haver um consenso sobre o referido tema.

Além das análises acerca das características pedagógicas percebidas através do questionário, buscou-se também investigar a frequência de uso da REBIO para a promoção da EA. Em relação à questão do uso da REBIO de Tinguá para a promoção da EA, das respostas obtidas, a maioria diz que a escola utiliza sim a reserva, no entanto, com pouca frequência, conforme apresentamos nas Figuras 2 e 3. 
Quadro II: Categorias e número de unidades de análise obtidas nas entrevistas semiestruturadas com os professores da Escola Estadual dos Lírios com relação às Concepções de EA

\begin{tabular}{|c|c|c|c|}
\hline Eixo Temático & \multicolumn{2}{|c|}{ Categorias e Tendências } & $\begin{array}{c}\mathrm{N}^{\circ} \text { de unidades de } \\
\text { análise/sentido }\end{array}$ \\
\hline \multirow{7}{*}{$\begin{array}{l}\text { 1- Concepções de } \\
\text { Educação Ambiental }\end{array}$} & \multicolumn{2}{|c|}{ 1.1 Cognitiva focada no individual } & 2 \\
\hline & \multicolumn{2}{|c|}{ 1.2 Romântica, preservacionista } & 5 \\
\hline & \multicolumn{2}{|c|}{ 1.3 Comportamentalista } & 1 \\
\hline & \multicolumn{2}{|c|}{ 1.4 Sensibilizadora } & ---- \\
\hline & \multirow{3}{*}{ 1.5 Crítica } & 1.5.1 Práxis & ---- \\
\hline & & 1.5.2 Relacional & 4 \\
\hline & & 1.5.3 Dimensão política & 1 \\
\hline
\end{tabular}

Fonte: Os autores, adaptado de Oliveira, 2012.

Figura 2: Professores que utilizam a REBIO de Tinguá como espaço formador na promoção de EA.

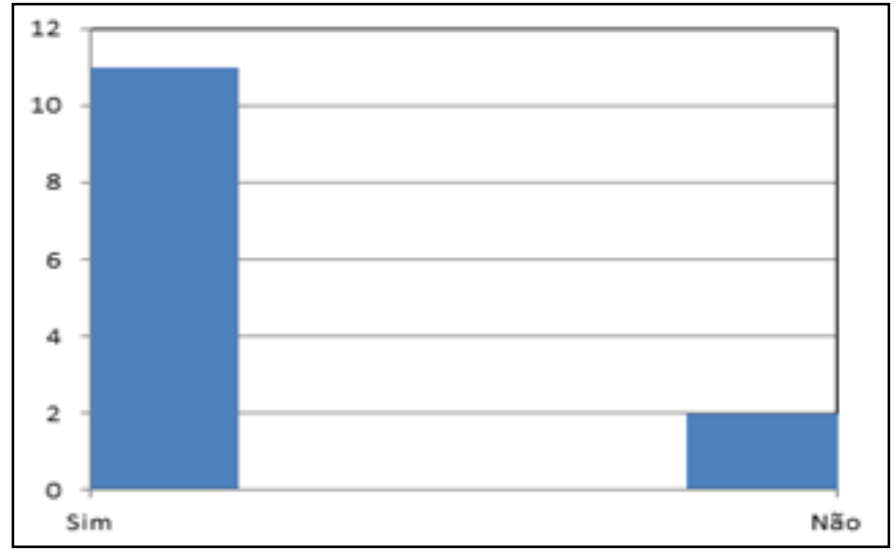

Fonte: Os próprios autores

No que tange ao uso da REBIO de Tinguá para a promoção da EA, percebeu-se que a maioria dos professores respondeu que faz uso deste espaço, no entanto, a frequência de uso é baixa conforme o gráfico a seguir. 
Figura 3: Frequência de uso da REBIO pelos professores ao longo do ano de 2017.

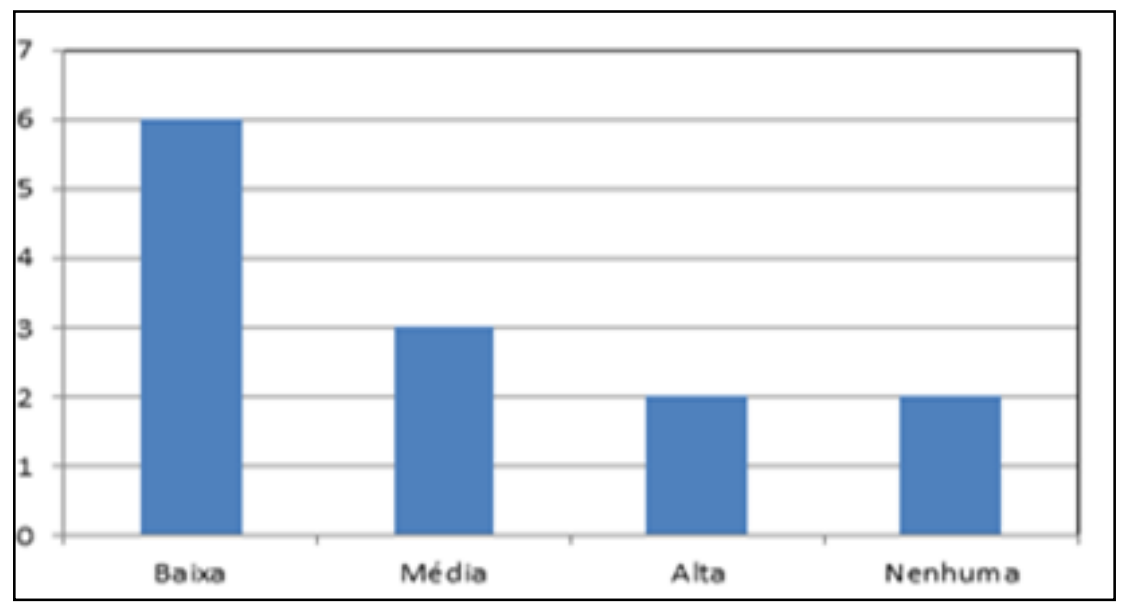

Fonte: Os próprios autores

De acordo com o referencial apresentado e com as análises dos questionários, concluímos que na escola em questão entre os professores que participaram da pesquisa, os quais compõem cerca de $80 \%$ do quadro docente da escola, a maioria se aproxima mais das macrotendências conservacionista e pragmática.

Portanto, de acordo com a proposta deste trabalho, podemos dizer que as práticas pedagógicas de EA da maioria desses professores estão embasadas na teoria da educação conservadora, na qual há um vazio de reflexão crítica acerca da ordem hegemonicamente estabelecida. Observa-se, no entanto, que apesar de a maioria estar embasada sob essas concepções, há uma tendência de mudança desse paradigma, uma vez que pela as análises, é possível percebermos um direcionamento das respostas às questões sociais e políticas e, em alguns casos, até mesmo questionando o atual modelo de sociedade.

Outro destaque é para o uso da REBIO de Tinguá como um espaço para a promoção da EA que, apesar de ser utilizado, a frequência de uso ainda é baixa. A questão latente é: de que forma o uso público de uma UC altamente restritiva pode proporcionar a promoção da EA?

Os problemas ambientais enfrentados atualmente não são pontuais, mas sim sistêmicos, o que exige uma mudança de paradigma e, para tal mudança, acredita-se que seja necessário um trabalho efetivo de uma educação ambiental capaz de analisar, discernir e intervir sobre o atual modelo de sociedade em que o mundo se encontra, e que essa intervenção se dá através, principalmente, da participação - neste caso embasada nos conceitos de uso público aqui defendidos.

O processo educacional se constitui no dia a dia, no cotidiano, nas inter-relações do ser com o ser e do ser com o meio - seja ele natural seja ele construído. Com isso, podemos considerar que "todo espaço e/ou estrutura traz em si características educativas, mas não necessariamente se constitui num espaço e/ou estrutura educadora, é preciso haver intencionalidade educadora, ou seja, intenção a propiciar-se aprendizagem aos nossos interlocutores" (MATAREZI, 2005, pág. 164). 
Uma das características que podemos destacar em todas as categorias de Unidades de Conservação é a determinação pelo SNUC de suas funções com finalidades para a promoção de EA. Essa característica nos indica o potencial que as UC possuem para que sejam, também, espaços educadores, pois, além de serem amparadas legalmente para a constituição desses espaços, elas possuem os elementos essenciais para tal finalidade, com destaque para as questões políticas e, principalmente, as questões ambientais.

Em se tratando das discussões políticas, as UC desde sua instituição, passam por um longo processo que envolve desde as pesquisas para fundamentar a implementação, até as discussões parlamentares para que seja definida sua categoria e por fim sua instituição. Após serem implementadas, as UC devem ter uma gestão, e essa gestão deve ser cumprida por toda a comunidade.

Acerca das questões ambientais, podemos destacar a importância do pertencimento e da constituição de identidade por parte dos sujeitos envolvidos com a EA a ser desenvolvida. Destacamos esses fatores no sentido de apropriação pelos indivíduos em relação ao lugar, pois acreditamos que

É no processo de apropriação, de territorialização, que as relações de identidade e pertencimento ao lugar são desenvolvidas, quando os sujeitos vão além da necessidade da apropriação de um espaço, quando desenvolvem ali valores ligados aos seus sentimentos e à sua identidade cultural e simbólica, recriando seu espaço de vida, ao qual se identificam e se sentem pertencer (RAFFESTIN, 1981 apud BORTOLETO, 2010, pág. 5).

Segundo Moreira (2006), ao criar essa identidade com o lugar, o sujeito cria também raízes, constituindo um enraizamento cultural. O mesmo considera que o espaço surge da relação de ambientalidade, ou seja, da relação estabelecida entre o homem e a natureza, de modo em que ambos coexistem. Dessa relação, surge a ideia de pertencimento que por fim cria esse enraizamento cultural.

Acerca desse enraizar-se, Cousin (2013) nos diz que:

Se o sujeito se sentir pertencente a um lugar, se liberta. Se enraizar, nutre-se do que há ali, criando sua identidade; pode então se libertar, ir para onde for que seus referenciais estarão claros, arraigados. Ou seja, pertencer, no sentido de identificarse com o um lugar ou um espaço, conhecer suas raízes, pode conduzir em direção à liberdade, à autonomia, a emancipação, a um sentido ontológico frente à vida, ao entorno, às pessoas (ibidem, pág. 9).

Portanto, a identidade caracteriza-se como um fator ímpar na promoção da Educação Ambiental. Uma vez que criada, não importa se o sujeito encontra-se em uma reserva biológica ou em um Shopping Center, suas ações serão guiadas de acordo com o seu enraizamento. Se suas raízes estiverem nutridas de consumo e avareza, suas ações possivelmente serão degradantes ao meio. Caso contrário, com raízes findadas em uma educação emancipada, suas ações serão, no mínimo, muito menos degradantes além de contribuir para a educação daqueles que estiverem próximos a ele.

\section{CONSIDERAÇÕES FINAIS}

O presente estudo buscou a análise da promoção da EA em uma escola do entorno da Rebio Tinguá. De acordo com os resultados alcançados, percebe-se que o uso da UC para 
promoção da EA por essa escola mostra-se ainda em estágio inicial, com ações pontuais e as macrotendências relacionadas à pedagogia tradicional de ensino, caracterizando certa fragilidade - segundo o referencial ao qual se embasa tal pesquisa - no que tange à emancipação dos sujeitos nela envolvidos.

Apesar de algumas categorias de UC serem caracterizadas por um uso mais restritivo, percebe-se a potencialidade de uma EA efetiva através desse uso. Para além, pensase nas diversas possibilidades de parcerias entre a gestão dessas UC juntamente a associações de moradores, escolas, enfim, com a comunidade circundante aos seus limites na busca por uma conservação mais eficiente. Além disso, a sociedade da Baixada Fluminense - região onde se encontra a maior parte da REBIO Tinguá - possui uma cultura caracterizada pelo respeito dos mais jovens às lideranças mais antigas, constituindo uma via potencial de acesso a esses jovens.

Devido às diversas realidades da sociedade contidas na escola e do público o qual é atendido por essa instituição - crianças e jovens, em sua maioria - enxerga-se essa instituição como um dos mais importantes locais para se iniciar o estímulo ao uso público com a finalidade da promoção da EA. Ora, é justamente nessa faixa de idade que o sujeito passa pelas maiores transformações educacionais as quais irão moldá-lo para a vida e, dessa maneira, o estabelecimento de uma educação a qual formará identidades concretas com ações e discursos pautados na importância ambiental, pode ser o início de uma necessária mudança de paradigma, a qual nos referimos anteriormente.

Durante o acompanhamento das atividades de educação ambiental realizadas pela a escola em seu entorno, percebeu-se o empenho dos atores envolvidos nessas atividades, desde a equipe da escola (faxineiros[as], cozinheiros[as], professores, coordenação) até os alunos, passando ainda pela própria comunidade que, ao perceber as ações dos alunos, se dispunha em ajudar sempre que necessário.

Devido ao uso da REBIO para a promoção da EA apresentar-se de forma incipiente, registra-se a necessidade de um plano de ação por parte das instituições envolvidas de modo a promover esse uso. Como sugestões, fica a indicação da criação de trilhas interpretativas na UC; participação das diretorias das escolas do entorno no conselho gestor a fim de levar propostas de trabalhos conjuntos e vice e versa, participação de membros da REBIO no planejamento dos Projetos Políticos Pedagógicos das escolas, levando, também, suas propostas de ações em comum. Destaca-se também a necessidade de políticas públicas voltadas para a temática, como por exemplo, a formação continuada aos professores a fim de buscarem novas metodologias de trabalhos, reconhecendo a importância dessa missão.

Conclui-se, portanto, que o simples ato de se criar uma UC não garante a preservação/conservação por completo do ambiente, mas sim de algumas "ilhas verdes". É necessário avançar a essas medidas consideradas paliativas. É necessário que haja uma mudança no atual paradigma cultural caracterizado por um sistema e forma de pensamento altamente degradante e essa mudança somente é possível através da reeducação ambiental. 


\section{REFERÊNCIAS}

BRASIL. Lei $\mathbf{n}^{\mathbf{0}}$ 9.985, de 18 de Julho de 2000. Regulamenta o artigo 225, § $1^{\circ}$, incisos I, II, III e VII da Constituição Federal, institui o Sistema Nacional de Unidades de Conservação da Natureza e dá outras providências. Ministério do Meio Ambiente, Brasília. Disponível em:http://www.planalto.gov.br/ccivil_03/leis/L9985.htm. Acesso em: 29 de maio de 2019.

BORTOLETO, E. M. Identidade, Território, E Pertencimento: A Comunidade Pomerana Em Pancas/Es e a Unidade De Conservação Dos Pontões Capixabas. Anais XVI Encontro Nacional dos Geógrafos. Realizado de 25 a 31 de julho de 2010. Porto Alegre - RS. 2010

COUSIN, C. S. Pertencimento ao lugar e a formação de educadores ambientais: um diálogo necessário. In:VII EPEA - Encontro Pesquisa em Educação Ambiental Rio Claro SP, 07 a 10 de Julho de 2013. Realização: UNESP campus Rio Claro e campus Botucatu, USP Ribeirão Preto e UFSCar.

GUIMARÃES, G. P. A Educação Ambiental nas Escolas de Tinguá: Desafios E Potencialidades nas Proximidades da Reserva Biológica. 2017. 71 f. Monografia (Graduação) - Curso de Geografia, DeGeo, Universidade Federal Rural do Rio de Janeiro, Nova Iguaçu, 2017. CD-ROM.

LAYRARGUES, P. P. (Re)Conhecendo A Educação Ambiental Brasileira. In: Identidades da educação ambiental brasileira / Ministério do Meio Ambiente. Diretoria de Educação Ambiental; Philippe Pomier Layrargues (coord.). - Brasília: Ministério do Meio Ambiente, 2004. 156 p.

LAYRARGUES, P. P.; LIMA. G. F. C. Mapeando as macro-tendências políticopedagógicas da educação ambiental contemporânea no Brasil. In: VI ENCONTRO DE PESQUISA EM EDUCAÇÂO AMBIENTAL, 2011, Ribeirão Preto-SP. Anais... Ribeirão Preto-SP, 2011. p. $1-15$

MATAREZI, J. Estruturas e espaços educadores: quando espaços e estruturas se tornam educadores. In: Luiz Ferraro Jr. (org.). Encontros e Caminhos I: formação de educadoras(es) ambientais e coletivos educadores, Brasília: MMA, Diretoria de Educação Ambiental, 2005 (p. 161-173).

MILLER, K. R. Evolução do conceito de áreas de proteção - oportunidades para o século XXI. In: Anais do I Congresso Brasileiro de Unidades de Conservação. Curitiba: IAP: UNILIVRE: Rede Nacional Pró Unidades de Conservação, Vol. 1: 3-21. 1997

MORAES, R. Uma tempestade de luz: a compreensão possibilitada pela análise textual discursiva. Ciência e Educação, v. 9, n. 2, p. 191-211, 2003.

MORAES, R; GALIAZZI, M. do C. Análise textual discursiva: processo reconstrutivo de múltiplas faces. Ciência e Educação, v. 12, n. 1, p. 117-128, 2006.

MOREIRA, R. Para onde vai o pensamento geográfico? Por uma epistemologia crítica. São Paulo: Contexto, 2006.

MINISTÉRIO DO MEIO AMBIENTE. Diretrizes para visitação em Unidades de Conservação. Brasília: MMA, 2006

OLIVEIRA, A. L. de, 1985-. A perspectiva participativa para a inserção da educação ambiental crítica em escolas da Baixada Fluminense. 2012. $143 \mathrm{f}$.

PIMENTEL, D. S. Parcerias para a gestão do uso público em parques. In: Anais - Uso Público em Unidades de Conservação, n. 1, v.1, Niteroi, 2013. Disponível em: http://www.uff.br/usopúblico. 
QUEIROZ, E. D. Uso Público no Parque Natural Municipal de Nova Iguaçu-RJ: trilhando entre possibilidades e dificuldades. Tese de Doutorado. Programa de PósGraduação em Geografia. UFF. Niterói, 2018

RAFFESTIN, C. Per uma geografia del potere. Milão: Unicopli, 1981. In: Bortoleto, E. M. Identidade, Território, E Pertencimento: A Comunidade Pomerana Em Pancas/Es E A Unidade de Conservação Dos Pontões Capixabas. Anais XVI Encontro Nacional dos Geógrafos. Realizado de 25 a 31 de julho de 2010. Porto Alegre - RS, 2010.

RODRIGUES, C.G.O.; IRVING, M.A. Os significados de "público" e o compromisso de inclusão social no acesso aos serviços de apoio ao turismo nos parques nacionais. In: IRVING, M.A; RODRIGUES, et al (Orgs.). Turismo, áreas protegidas e inclusão social: diálogos entre saberes e fazeres. $1^{a}$ ed. - Rio de Janeiro: Folio Digital: Letra e Imagem, 2015

SILVA, D. Q. e SOUZA, G.M. Análise exploratória através de estatística espacial: um estudo de caso na Reserva Biológica do Tinguá. In: Anais do XVII Simpósio de Geografia Física Aplicada. I Congresso Nacional de Geografia Física. UNICAMP, Campinas, SP. p. 67636772. 2017

TAKAHASHI, L. Uso público em unidades de conservação. Cadernos de Conservação, Curitiba, vol.2, $\mathrm{n}^{\mathrm{o}} 2,2004$.

THOMAS, K. 1983. O homem e o mundo natural. São Paulo: Cia. das Letras.

VALLEJO, L. R. Unidades de Conservação: Uma discussão teórica à luz dos conceitos de território e de políticas públicas. GEOgraphia (UFF), Rio de Janeiro, ano 4, n. 8, p. 77-106, 2003. 